\title{
Delay in Pulmonary Glycogen Degradation in Fetuses of Streptozotocin Diabetic Rats
}

\author{
IRA H. GEWOLB, ${ }^{(47)}$ CAROLYN BARRETT, CHRISTINE M. WILSON, AND \\ JOSEPH B. WARSHAW ${ }^{(48)}$ \\ Department of Pediatrics, Division of Perinatal Medicine, Yale University School of Medicine, New Haven, \\ Connecticut, USA
}

\section{Summary}

The developmental profile of pulmonary glycogen was investigated in fetuses of rats made diabetic before conception with the injection of $40 \mathrm{mg} / \mathrm{kg}$ streptozotocin.

Lungs of control litters showed increasing pulmonary glycogen concentration from day 16-20, followed by significant decline by term (= 22 days). In contrast, the diabetic litters, which had pulmonary glycogen concentration equal to controls until day 20 , showed significantly higher glycogen values $(P<0.01)$ on days 21 and 22 , consistent with a delay in glycogen degradation. This coincided with the finding of decreased amounts of fetal pulmonary phosphatidylcholine and disaturated phosphatidylcholine on day 21 of the diabetic gestation $(P<0.05)$, but not before that time.

Pulmonary glycogen phosphorylase $A$ activity was significantly decreased in the diabetic litters on the final days of gestation, at the same time that the delay in glycogen breakdown became evident. Pulmonary glycogen synthase activity did not differ in the control and diabetic fetuses.

\section{Speculation}

The delay in pulmonary glycogen degradation seen in the fetus of the diabetic gestation is thus temporally related to the delay in lung maturation seen in this model and may be secondary to a decrease in the activity of the glycogenolytic enzyme phosphorylase A. Decreased availability of pulmonary glycogen stores for surfactant synthesis may be important in elucidating the mechanism of the delayed pulmonic maturation seen in fetuses of diabetic pregnancies.

There is a growing body of evidence that implicates glucose, and its storage form glycogen, in the biosynthesis of surface active phospholipids in the developing fetus $(11,36,42)$. Pulmonary glycogen content, which increases throughout most of gestation, falls rapidly near term, coincident with the appearance of lamellar bodies in alveolar type II cells and with an increase in choline incorporation into the surface active phospholipid fraction (27, 44). These maturational processes-the fall in pulmonary glycogen, the rise in surfactant synthesis, and the appearance of lamellar bodies-are all accelerated by the administration of exogenous glucocorticoids $(14,23,29,31,32)$.

In a retrospective analysis, Robert et al. (31) showed that infants of diabetic pregnancies have a 5.6 times greater risk of developing the respiratory distress syndrome than those of nondiabetic gestations. It might therefore be expected that fetuses of diabetic pregnancies would have coincident aberrations in surfactant production and pulmonary glycogen metabolism. Indeed, increased pulmonary glycogen stores have been observed in fetal (39) and newborn (35) animals born to diabetic mothers; however, others report diminished glycogen content in the lungs of fetuses of experimental diabetic pregnancies (43).

We used the streptozotocin diabetic rat as a means of studying fetal pulmonary glycogen metabolism throughout the diabetic gestation, in an effort to clarify the role of substrate availability with respect to the observed delay in lung maturation seen in the diabetic pregnancy $(4,31,39,40)$. In addition, the activities of enzymes of glycogen synthesis and breakdown were measured in order to gain an understanding of control mechanisms of glycogen metabolism in the developing fetal lung and its relationship to phospholipid synthesis.

\section{MATERIALS AND METHODS}

The diabetic state was induced in nonpregnant adult female Sprague-Dawley rats (Charles River Breeding Laboratories, Cambridge, MA) by the intravenous injection of $40 \mathrm{mg} / \mathrm{kg}$ of streptozotocin (courtesy of Upjohn Co., Kalamazoo, MI), a potent and specific pancreatic beta-cell cytotoxin (20), dissolved in $0.1 \mathrm{M}$ sodium citrate buffer, $\mathrm{pH}$ 4.5. Control females were injected with an equivalent amount of buffer solution. Standard rat chow and water were offered ad libitum.

The females were then caged with adult male rats each night. Mating was confirmed by the presence of a copulatory plug and sperm on a vaginal swab. The morning after mating occurred was designated day 1 of gestation.

Blood samples for glucose and insulin determination were obtained before injection and again at time of decapitation. Determination of ketonemia was done at time of killing using Acetest tablets (Ames Co., Elkhart, IN).

Animals were killed by decapitation from day 16 through term (day 22). The uteri were rapidly removed and immediately placed on ice. Fetuses were then killed by decapitation, and blood was collected for glucose and insulin determination, after which the fetal lungs were dissected free of nonpulmonary tissue and were frozen in glass tubes in an ethanol/dry ice bath within $15 \mathrm{sec}$ of decapitation. Lungs were then stored at $-70^{\circ} \mathrm{C}$. until analyzed. Two to four fetuses from each litter were set aside for determination of lung and body weights.

Glycogen content was assayed using a previously described modification (27) of the method of Lowry and Passoneau (26), in which the fluorometric measurement of NADPH generated from glucose-6-phosphate is used as an index of glycogen concentration.

Glycogen synthase (EC 2.4.1.11) activity (' $A$ ' and total) was determined by measuring the rate of incorporation of $\left[{ }^{14} \mathrm{C}\right]$-glucose from UDP- $\left[{ }^{14} \mathrm{C}\right]$-glucose into glycogen, as described by Eisen et al. (9) and modified for fetal rat lung by Maniscalco et al. (27).

Glycogen phosphorylase (EC 2.4.1.1) activity was measured in the direction of glycogen breakdown, using a modification of previously described methods $(27,38)$. The frozen lungs were homogenized on ice in 10 volumes $(w / v)$ of a solution containing $100 \mathrm{mM} \mathrm{NaF}$ and $50 \mathrm{mM}$ tris-succinate buffer, pH 6.9. For determination of glycogen phosphorylase $\mathrm{A}$, the homogenate was then preincubated with $5^{\prime}$ adenylic acid deaminase (EC 3.5.4.6; Sigma Chemical Co., St. Louis, MO) 3.4 units $/ \mathrm{ml}$ homogenate, for $15 \mathrm{~min}$ in a $30^{\circ} \mathrm{C}$ water bath (33) to remove endogenous $5^{\prime}$ 
AMP, a potent stimulator of phosphorylase B activity (41). Glycogen phosphorylase $A$ activity was then measured by adding the homogenate to an assay mix consisting of $50 \mathrm{mM}$ imidazole buffer, $\mathrm{pH} 6.9,30 \mathrm{mM} \mathrm{NaF}, 3 \mathrm{mM} \mathrm{KH} \mathrm{PO}_{4}, 0.2 \mathrm{mM}$ EDTA, $0.7 \mathrm{mg} / \mathrm{ml}$ glycogen, 0.9 units/ml glucose-6-phosphate dehydrogenase, 0.45 units $/ \mathrm{ml}$ phosphoglucomutase, and $0.4 \mathrm{mM}$ caffeine. The rate of NADPH generation was measured on a fluorimeter (Perkin-Elmer Co., Norwalk, CT) on the linear part of the assay curve. For total phosphorylase $(\mathrm{A}+\mathrm{B})$ determination, a preincubation with a solution of $60 \mathrm{mM} \mathrm{ATP}$ and $200 \mathrm{mM} \mathrm{MgCl} 2, \mathrm{pH} 7.0,100 \mu \mathrm{l} / \mathrm{ml}$ homogenate, for $30 \mathrm{~min}$ in a $30^{\circ} \mathrm{C}$ water bath, was performed (33). Activity was then assayed as for phosphorylase $A$, except in medium without caffeine, but with the addition of $1.5 \mathrm{mM} 5^{\prime}$ AMP.

Lipids were extracted with chloroform and methanol according to the method of Bligh and Dyer (3). After thin layer chromatography (27), phospholipids were quantified by phosphorus determination (2). Disaturated phosphatidylcholine was isolated after oxidation with $\mathrm{OsO}_{4}$ according to a modification of the procedure of Mason et al. (28).

Protein content was assayed using the method of Lowry (25). DNA concentration was measured as described by Hill and Whatley (18). Determination of plasma glucose concentration was done using an automated glucose oxidase method (YSI model 23A Glucose Analyzer; Yellow Springs Instrument Co., Yellow Springs, $\mathrm{OH}$ ). Insulin was measured according to the method of Rosselin et al. (34).

All enzymes and biochemicals were obtained from Sigma Co., St. Louis, MO. UDP- $\left[{ }^{14} \mathrm{C}\right]$-glucose was obtained from New England Nuclear, Boston, MA.

Statistical calculations used the Student $t$ test; one-tailed analysis was used when appropriate (12). Arcsine transformation (phi) was used when ratios were analyzed (7).

\section{RESULTS}

Streptozotocin injection resulted in a manifest diabetic state, with the animals exhibiting polyuria, polydipsia, and glucosuria. As seen in Table 1, the mean maternal plasma glucose concentration at the time of termination of pregnancy was $498 \pm 11$ (S.E.) $\mathrm{mg} \%$ versus $104 \pm 2 \mathrm{mg} \%$ for the control mothers. Acetonemia was not seen in the diabetic group, in agreement with other studies $(10,21)$.

Fetal hyperglycemia was also manifested by the diabetic group, with plasma glucose concentrations of $355 \pm 10 \mathrm{mg} \%$ versus $51 \pm$ $4 \mathrm{mg} \%$ for the control group. Expressed as a percentage of concurrent maternal blood sugar concentration, the diabetic fetuses had levels approximating 70\% of maternal values, as opposed to only about $50 \%$ for the control litters. Fetal hyperinsulinemia was not present, the diabetic litters having insulin levels of $75 \pm$ 8 (S.E.) $\mu \mathrm{U} / \mathrm{ml}$ versus $83 \pm 9 \mu \mathrm{U} / \mathrm{ml}$ for the controls. In fact, relative to their blood glucose levels, the diabetic litters were hypoinsulinemic.

Litter size was slightly, but not significantly, decreased in the diabetic group: $11.9 \pm 0.5$ (S.E.) versus $13.2 \pm 0.4$ (Table 1 ).

There was a consistent diminution in the size of the diabetic fetuses for each day under study (Table 2). When compared with control fetuses, there was significant growth retardation in the

Table 1. Characteristics of the streptozotocin diabetic rat ${ }^{1}$

\begin{tabular}{llcc}
\hline & & Diabetic & Control \\
\hline Plasma glucose $(\mathrm{mg} \%)$ & Maternal & $498 \pm 11^{2}$ & $104 \pm 2$ \\
& Fetal & $355 \pm 10^{2}$ & $51 \pm 4$ \\
Insulin $(\mu \mathrm{U} / \mathrm{ml})$ & Maternal & $22 \pm 3^{2}$ & $46 \pm 5$ \\
& Fetal & $75 \pm 8$ & $83 \pm 9$ \\
& Litter size & $11.9 \pm 0.5$ & $13.2 \pm 0.4$ \\
\hline
\end{tabular}

\footnotetext{
${ }^{1}$ All data represents the mean \pm S.E. for the group. $N=50$ for each group which includes all gestational ages.

${ }^{2} P<0.001$
}

Table 2. Weights of Diabetics Expressed as a \% of control values ${ }^{1}$

\begin{tabular}{cccccc}
\hline $\begin{array}{c}\text { Day of } \\
\text { gestation }\end{array}$ & Body & Brain & Lung & Liver & Placenta \\
\hline 16 & $84^{2}$ & & & & 81 \\
18 & $78^{2}$ & $73^{2}$ & 85 & 101 & 129 \\
19 & $77^{3}$ & $85^{2}$ & $70^{3}$ & $77^{3}$ & $154^{3}$ \\
20 & $86^{2}$ & $76^{3}$ & $76^{3}$ & $78^{2}$ & $146^{3}$ \\
21 & $80^{2}$ & 90 & $83^{3}$ & $72^{3}$ & $141^{3}$ \\
22 & $75^{4}$ & $79^{4}$ & $77^{2}$ & $72^{3}$ & $159^{3}$ \\
\hline
\end{tabular}

${ }^{1}$ Weights of the offspring of diabetic gestations expressed as a \% of control values. $P$ values represent comparisons of the mean weight of each group.

$$
\begin{aligned}
& { }^{2} P<0.05 . \\
& { }^{3} P<0.01 . \\
& { }^{4} P<0.001 .
\end{aligned}
$$

\begin{tabular}{|c|c|c|c|c|}
\hline \multirow{2}{*}{$\begin{array}{l}\text { Day of } \\
\text { gestation }\end{array}$} & \multicolumn{2}{|c|}{$\begin{array}{l}\text { Lung protein }(\mathrm{mg} / \mathrm{g} \text { wet } \\
\text { weight) }\end{array}$} & \multicolumn{2}{|c|}{$\begin{array}{l}\text { Lung DNA (mg/g wet } \\
\text { weight) }\end{array}$} \\
\hline & Control & Diabetic & Control & Diabetic \\
\hline 16 & $65.5 \pm 4.9$ & $63.8 \pm 11.3$ & $7.27 \pm 2.12$ & $8.14 \pm 0.38$ \\
\hline 18 & $74.7 \pm 7.7$ & $60.4 \pm 5.3$ & $6.51 \pm 0.58$ & $7.13 \pm 0.64$ \\
\hline 19 & $71.5 \pm 3.7$ & $68.6 \pm 3.1$ & $8.46 \pm 0.70$ & $7.59 \pm 0.36$ \\
\hline 20 & $79.0 \pm 3.8$ & $78.9 \pm 6.8$ & $9.48 \pm 0.65$ & $9.61 \pm 0.78$ \\
\hline 21 & $81.7 \pm 3.7$ & $78.5 \pm 3.1$ & $9.49 \pm 0.43$ & $9.92 \pm 0.41$ \\
\hline 22 & $80.9 \pm 3.9$ & $70.5 \pm 2.3^{1}$ & $7.92 \pm 0.24$ & $8.13 \pm 0.43$ \\
\hline
\end{tabular}

Table 3. Protein and DNA concentrations/g wet weight in lungs of diabetic and control fetuses

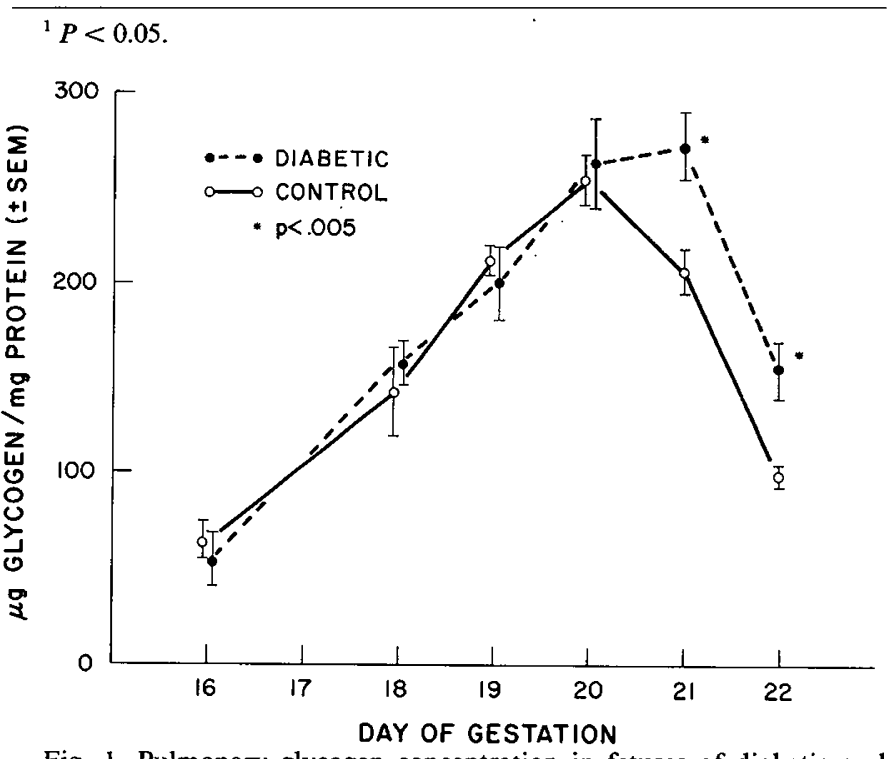

Fig. 1. Pulmonary glycogen concentration in fetuses of diabetic and control pregnancies. Each point represents the mean \pm S.E. of an average of eight litters.

three fetal organs examined (brain, liver, and lung), each of which was approximately $20-30 \%$ reduced in weight. In contrast, placentas of the diabetic group were markedly increased in weight from the 18th day on. Dry/wet weight ratios did not differ in the two groups.

Pulmonary DNA concentration in the diabetic litters were not different from control values (Table 3); protein concentration was somewhat diminished in the diabetic group, but attained statistical significance only on day 22 (Table 3).

Figure 1 represents pulmonary glycogen concentration in the diabetic and control litters as a function of gestational age. Lungs of control litters showed an increasing pulmonary glycogen content from day 16 to day 20 , peaking at $256 \mu \mathrm{g} / \mathrm{mg}$ protein, followed by a significant decline by term ( 22 days). In contrast, the diabetic litters, which had pulmonary glycogen concentrations equal to 
control values on days $16,18,19$, and 20 , showed significantly higher glycogen values on days 21 and 22 , consistent with a delay in glycogen degradation.

Glycogen synthase, responsible for the addition of UDP-glucose moieties to the elongating glycogen chain, is thought to exist in at least two interconvertible forms: ' $A$ ' (dephosphorylated), thought to be the active form, and ' $B$ ', the inactive, phosphorylated form (24). Total $(A+B)$ glycogen synthase activity, expressed as pmole UDPG incorporated $/ \mathrm{min} / \mathrm{mg}$ protein, is shown in Figure 2 . Both diabetic and control lungs showed a 3-fold increase in synthase activity from day 18 to day 22 , and no significant differences were evident between the two groups. Glycogen synthase A activity also showed an approximately 2 -fold increase over the period from day 18 to 22 (Fig. 3). Again, no significant differences were noted between diabetic and control lungs. When expressed as the ratio of active/total activity [Fig. 4, ratios are compared after using the arcsine transformation (7)] both the diabetic and control litters showed a decline from approximately 0.29 to 0.15 from days 19 to 22 , coincident with the decline in glycogen concentration late in gestation.

Glycogen phosphorylase, the rate limiting enzyme in glycogen

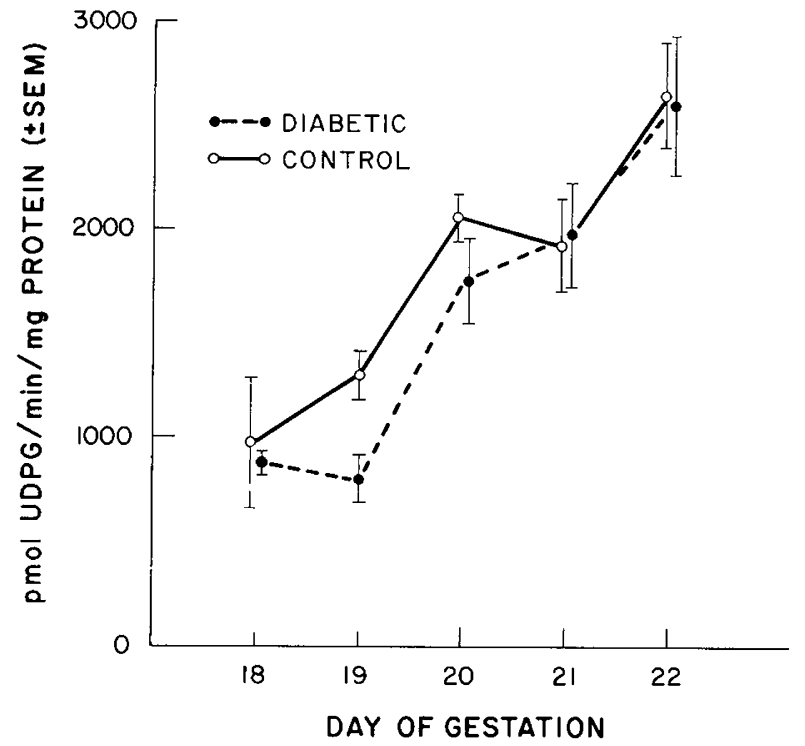

Fig. 2. Total $(A+B)$ glycogen synthase activity in the lungs of fetuses of diabetic and control pregnancies. No significant differences are seen. Each point represents the mean \pm S.E. of an average of eight litters.

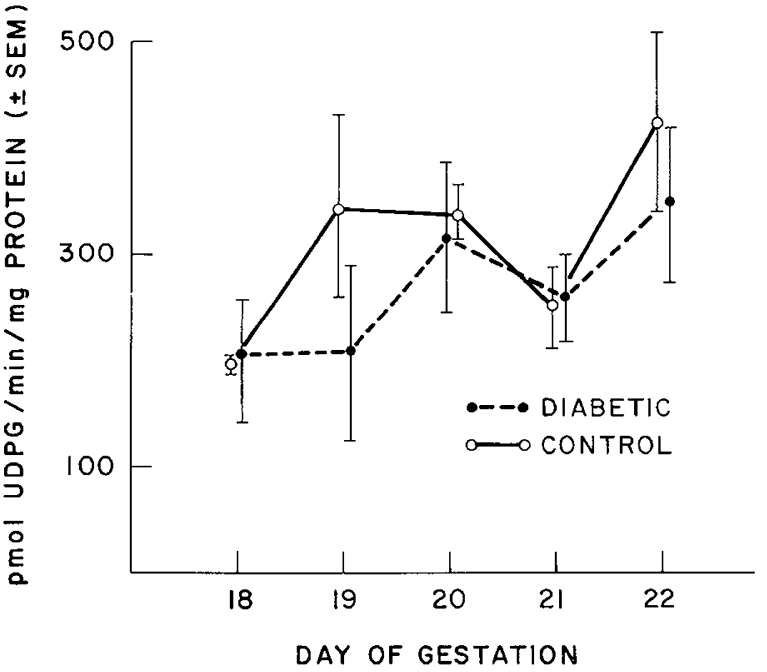

Fig. 3. Active (A) glycogen synthase activity in the lungs of fetuses of diabetic and control pregnancies. No significant differences are seen. Each point represents the mean \pm S.E. of an average of eight litters.

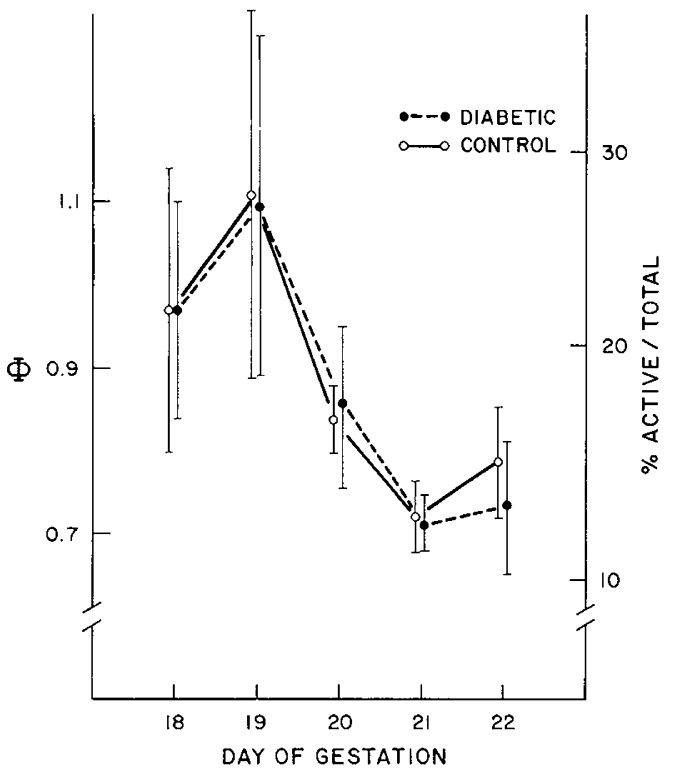

Fig. 4. Active/total synthase activity. $\phi, 2$ arcsine $\mathrm{A} /$ total, used to compare ratios. Corresponding percentages are depicted on the right of the figure.

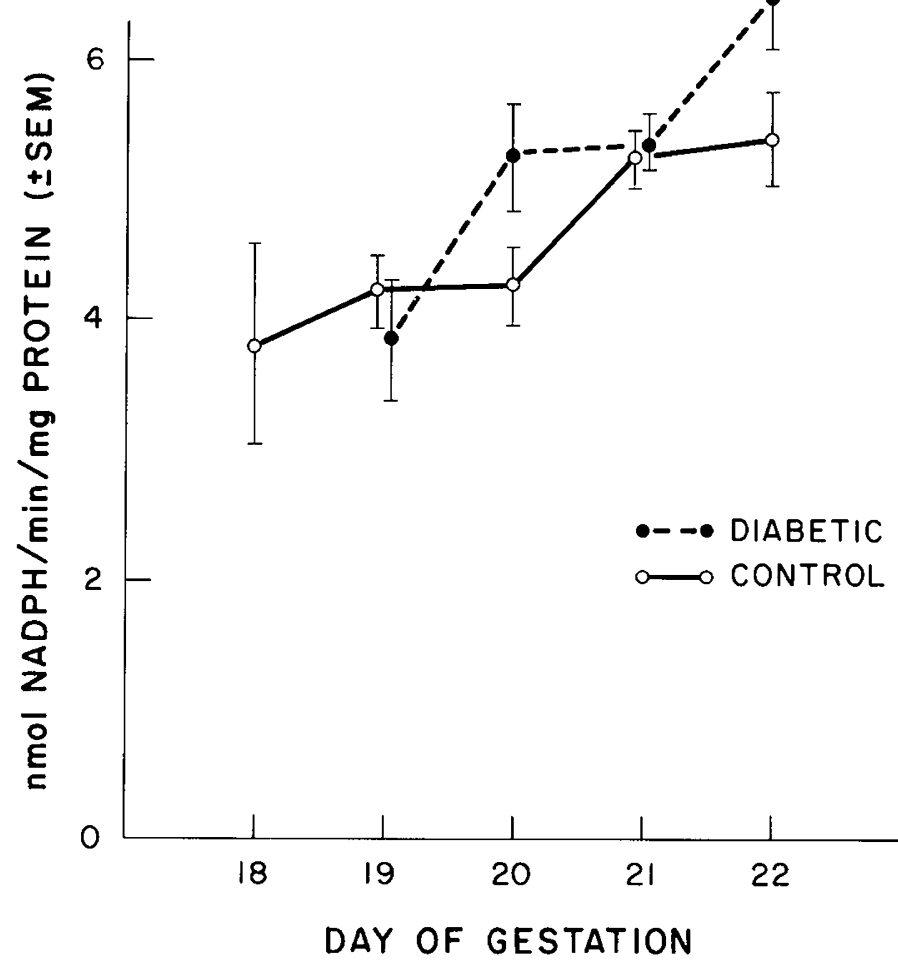

Fig. 5. Total $(A+B)$ pulmonary glycogen phosphorylase in fetuses of diabetic and control gestations. No significant differences are noted. Each point represents the mean \pm S.E. of an average of eight litters.

degradation (17) also exists in two interconvertible forms: ' $A$ ', the active phosphorylated form and ' $B$ ', the inactive enzyme. As seen in Figure 5, no significant differences were found in the total (A + B) phosphorylase activity between the diabetic and control litters, both of which showed an increase with increasing gestational age. The diabetic animals appeared to have significantly decreased activity of the active (A) enzyme on the final three days of gestation (Fig. 6), precisely the time when the delay in glycogen breakdown became evident. Similarly, the ratio of active/total (corrected using the arcsine transformation (7)) activity in the diabetics was significantly decreased from day 20 to day 22 (Fig. 7). 


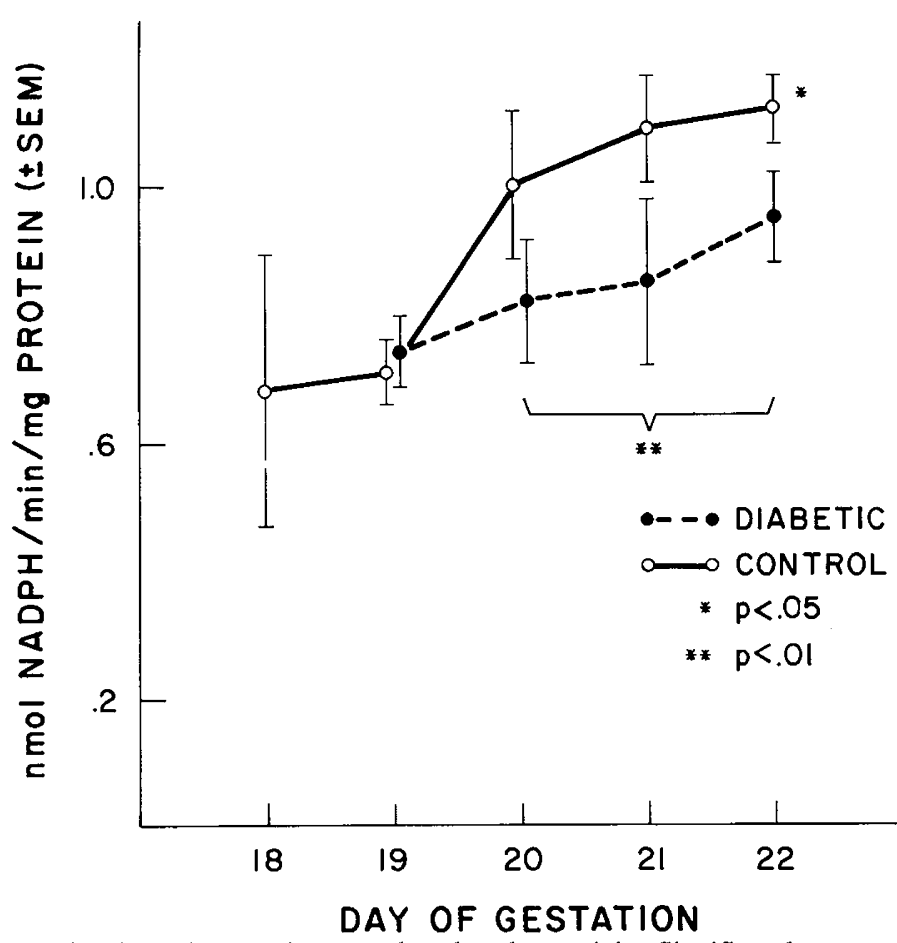

Fig. 6. Active (A) glycogen phosphorylase activity. Significantly greater activity is seen in the control group on day 22, and when days 20-22 are analyzed as a group. Each point represents the mean \pm S.E. of an average of eight litters.

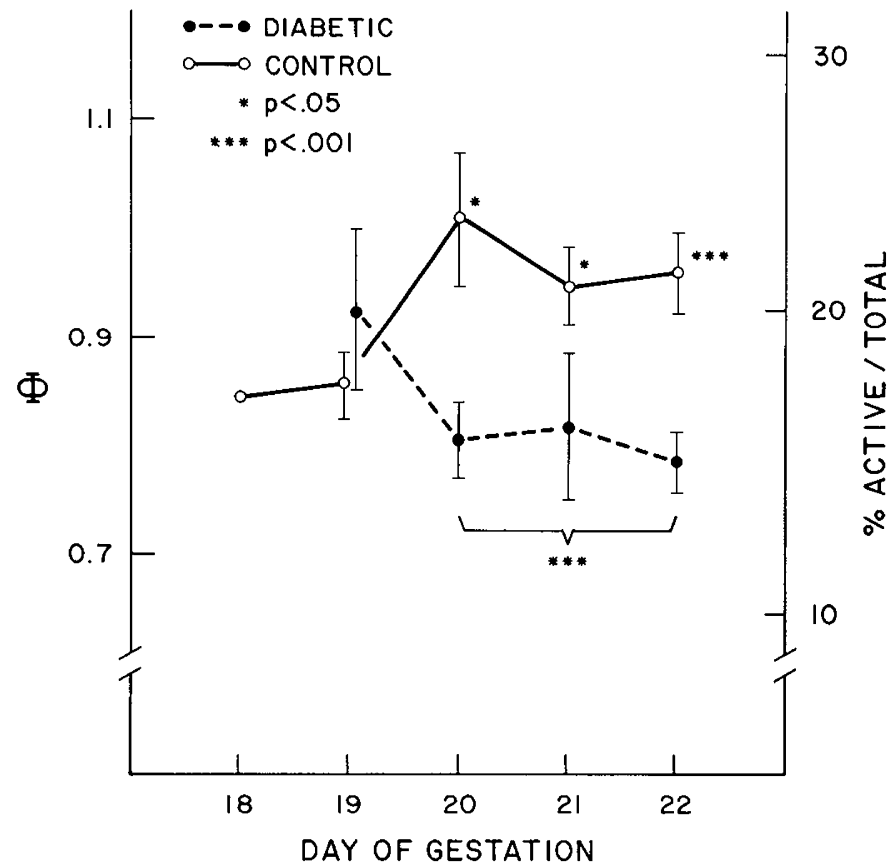

Fig. 7. \% active/total phosphorylase activity, expressed using $\phi$, the arcsine transformation, with the corresponding percentages depicted on the right. Significant differences are seen on each of the last three days of gestation.

Table 4 expresses the results of the analysis of total phospholipid, phosphatidylcholine, and disaturated phosphatidylcholine for day 21 in diabetic and control fetuses. Lungs of diabetic litters had small, but significant, decreases in all three parameters, consistent with a delay in lung maturation. No significant differences were noted on days 19,20 , and 22 (13).

\section{DISCUSSION}

We have demonstrated that the lungs of fetuses of diabetic rat pregnancies follow a normal pattern of glycogen deposition until the 20th day of gestation, after which time pulmonary glycogen
Table 4. Surface active phospholipids on day $21^{1}$

\begin{tabular}{lccc}
\hline & $\begin{array}{c}\text { Total phospholip- } \\
\text { ids }\end{array}$ & $\begin{array}{c}\text { Phosphatidylcholine } \\
\text { (PC) }\end{array}$ & Disaturated PC \\
\hline Diabetic & $5.84 \pm 0.12^{3}$ & $2.95 \pm 0.09^{2}$ & $0.90 \pm 0.05^{2}$ \\
Control & $6.42 \pm 0.16$ & $3.30 \pm 0.10$ & $1.03 \pm 0.04$ \\
\hline
\end{tabular}

${ }^{1}$ Results expressed as $\mu \mathrm{g}$ phosphorus/mg protein.

${ }^{2} P<0.05$.

${ }^{3} P<0.01$.

concentration is significantly increased compared to controls. This finding has been related to a decrease in the accumulation of surface active phospholipids in the diabetic offspring, occurring at the same time in gestation (day 21). These data support the concept of glycogen as a substrate for surfactant synthesis and provide evidence for a relationship between lung glycogen and lung functional maturation. Because glucose metabolism is important in the biosynthesis of surface active phospholipids in the adult lung $(11,36,42)$, it is likely that it is similarly important in the fetal lung. Pulmonary glycogen stores rise early in normal pregnancy, only to decline late in gestation, concurrent with the rapid rise in phosphatidylcholine synthesis (27). Gilden et al. (14) showed that glucocorticoid administration resulted in a decrease in pulmonary glycogen content and a significantly enhanced incorporation of radioactive glucose into both glycogen and phosphatidylcholine. In view of the increased glucose consumption and glycogen turnover rates, coupled with the increased incorporation of glucose into phosphatidylcholine, it was suggested that glycogen is a source of glucose for surfactant synthesis. Both normal lung maturation (44) and maturation accelerated by exogenous steroids $(23,29,32)$ have been correlated with rapid declines in pulmonary glycogen stores, also suggesting a role for glycogen as a substrate source in surfactant synthesis.

Previous studies $(5,27)$ on normal gestation demonstrated a correlation between increasing activity of phosphorylase A and glycogen depletion. Our data is in good agreement with these findings and suggests that an increase in phosphorylase A activity leads to degradation of pulmonary glycogen in the developing lung. Similarly, active/total phosphorylase is low during glycogen accumulation and rises concomitant with its breakdown.

When expressed as a ratio of active/total glycogen synthetase, the data also suggest a correlation between glycogen accumulation and increased ratio of active/total synthase, and between breakdown and decreased active/total synthase in both the diabetics and controls. The differences in glycogen concentration seen late in the diabetic gestation could not be accounted for by synthase A measurements. Intermediate forms of synthase, $(22,37)$ however, may be important in glycogen regulation in the diabetic gestation.

Our data helps explain discrepancies between various studies showing either an increase $(35,39)$ or a decrease $(43)$ in pulmonary glycogen content in the diabetic pregnancy, and highlights the importance of following a rapidly changing parameter throughout development. No differences will be seen early in development; only late in gestation, i.e., after day 20 in the rat pregnancy, will the increase in glycogen content become evident.

The concept of substrate regulation of glycogen metabolism has been well studied in the liver (17). Phosphorylase A concentration appears to be a major factor in the control of glycogen metabolism in the liver, because this enzyme controls the rate limiting step in glycogen breakdown, and also, by controlling synthase phosphatase, inhibits synthase A (17). Glucose itself inhibits phosphorylase A by decreasing site affinity of the enzyme for glucose-1-phosphate binding sites. It also markedly activates phosphorylase phosphatase, thus decreasing phosphorylase A activity (19), and increases synthase $A$, probably via phosphorylase A mediated synthase phosphatase inhibition $(6,15,17)$. This scheme would appear, on the basis of our data, to be applicable to the fetal lung as well, with fetal hyperglycemia possibly resulting in decreased phosphorylase A activity, in turn leading to decrease in glycogen breakdown at a time when degradative processes usually predominate. 
Our diabetic model differs from the human diabetic pregnancy in that it does not display hyperinsulinemia, a finding consistent with other investigators using this model, who found either no change $(16,30)$ or a decrease $(10)$ in fetal plasma insulin, and a degranulation of fetal pancreatic beta cells in spite of islet hypertrophy and beta cell hyperplasia (1). In fact, the fetuses are relatively hypoinsulinemic with respect to their blood sugars, suggesting intrauterine beta cell exhaustion. This would also go along with the lack of macrosomia noted in this model $(8,16,30)$. Bose et al. (4) also noted equivalent fetal insulin levels, a decreased fetal glucose/insulin ratio and a lack of tissue overgrowth in their alloxan rabbit model. The injection of the rats prior to impregnation negates the possibility of a direct toxic effect of streptozotocin on the fetal pancreas.

The delay in lung maturation seen in this model may thus be the result of substrate excess, rather than hyperinsulinemia, just as the changes in glycogen metabolism would appear to be under the regulation of substrate rather than insulin. However, insulin levels alone may not be sufficient to characterize the diabetic fetuses; insulin receptor number and affinity may be of considerable importance. We hypothesize the substrate excess could lead to delayed fetal lung maturation either by an interference with the utilization of glycogen as a substrate source in surfactant synthesis, or, alternatively, by suppression of the glucocorticoid surge late in gestation. We can thus speculate that substrate excess directs the organism to growth rather than maturation.

In summary, we have found that pulmonary glycogen concentration in the fetus of the streptozotocin diabetic rat follows a normal pattern until the final two days of gestation, after which time a delay in glycogen degradation occurs. This delay in glycogen breakdown may be secondary to a decrease in the activity of the glycogenolytic enzyme phosphorylase A, resulting from an excessive glucose milieu. Glycogen synthase activity appears less important in the regulation of pulmonary glycogen metabolism late in gestation, recognizing, of course, that enzyme activities measured under ideal in vitro conditions may not accurately reflect the actual in vivo situation. If the breakdown of pulmonary glycogen is indeed an important event in providing substrate for the synthesis of surface active materials, the finding of increased glycogen may help in elucidating a mechanism of the delayed pulmonic maturation seen in fetuses of diabetic pregnancies.

\section{REFERENCES AND NOTES}

1. Aerts, L. and Van Assche, F. A.: Rat foetal endocrine pancreas in experimental diabetes. J. Endocrinol., 73: 339 (1977).

2. Bartlett, G. R.: Phosphorus assay in column chromatography. J. Biol. Chem. 234: 466 (1959).

3. Bligh, E.C. and Dyer, W. J.: A rapid method of total lipid extraction and purification. Can. J. Biochem. Physiol., 37: 911 (1959).

4. Bose, C. L., Mann, D. N., D'Ercole, A. J., and Lawson, E. E.: Delayed feta pulmonary maturation in a rabbit model of the diabetic pregnancy. J. Clin. Invest., 66: 220 (1980).

5. Brandstrup, N. and Kretcher, N.: The metabolism of glycogen in the lungs of the fetal rabbit. Dev. Biol., 11: 202 (1965).

6. Buschiazzo, H., Exton, J. H., and Park, C. R.: Effects of glucose on glycogen synthetase, phosphorylase, and glycogen deposition in the perfused rat liver. Proc. Nat. Acad. Sci., 65: 383 (1970).

7. Cohen, J.: Statistical Power Analysis for the Behavior Sciences. Academic Press, N.Y. chap. 6 (1977).

8. Demottaz, V., Epstein, M. F., and Frantz, I. D.: Phospholipid synthesis in lung slices from fetuses of alloxan diabetic rabbits. Pediatr. Res., 14: 47 (1980)

9. Eisen, H. J., Goldfine, I. D., and Glinsmann, W. H.: Regulation of hepatic glycogen synthesis during fetal development: Roles of hydrocortisone, insulin, and insulin receptors. Proc. Nat. Acad. Sci. (USA), 70: 3454 (1973).

10. Eriksson, V., Andersson, A., Effendic, S., Elde, R., and Hellerstrom, C.: Effects on the foetal and newborn rat with respect to birthweight, insulin concentration and pancreatic contents of insulin, glycogen, and somatostatin. Acta Endocrinol., 94: 354 (1980).

11. Felts, J. B.: Biochemistry of the lung. Health Phys., 10: 973 (1974).

12. Ferguson, G. A.: Statistical Analysis in Psychology and Education, p. 177 (McGraw-Hill, New York, New York 1981).

13. Gewolb, I. H., Wilson, C. M., Barrett, C., Light, D., Smith, G. J. W., and Warshaw, J. B.: Unpublished data.

14. Gilden, C., Sevanian, A., Tierney, D. F., Kaplan, S. A., and Barrett, C. T. Regulation of fetal lung phosphatidylcholine synthesis by cortisol: Role of glycogen and glucose. Pediatr. Res., 11: 845 (1977).
15. Glinsmann, W., Pauk, G., and Hern, E.: Control of rat liver glycogen synthetase and phosphorylase activities by glucose. Biochem. Biophys. Res. Comm., 39: 774 (1970).

16. Golob, E. K., Rishi, S., Becker, K. L., Moore, C., and Shah, N.: Effect of streptozotocin induced diabetes mellitus on pancreatic insulin content of the fetus. Diabetes, 19: 610 (1970).

17. Hers, H. G.: The control of glycogen metabolism in the liver. Annu. Rev. Biochem., 45: 167 (1976).

18. Hill, B. T. and Whatley, S.: A simple rapid microassay for DNA. FEBS Letters 56(I): 20 (1975).

19. Holmes, P. A. and Mansour, T. E.: Glucose as a regulator of glycogen phosphorylase in rat diaphragm. 1 . The effect of glucose and related compounds on phosphorylase and glycogen levels. Biochim. Biophys. Acta, 156: 266 (1968).

20. Junod, A., Lambert, A. E., Orci, L., Pictet, R., Gonet, A. E., and Renold, A. E. Studies of the diabetogenic action of streptozotocin. Proc. Soc. Exp. Biol. Med., 126: 201 (1967).

21. Junod, A., Lambert, A. E., Stauffacher, W., and Renold, A. E.: Diabetogenic action of streptozotocin: Relationship of dose to metabolic response. J. Clin. Invest., 48: 2129 (1969).

22. Kaslow, H. R., Eichner, R. D., and Mayer, S. E.: Interconversion between multiple glucose-6-phosphate-dependent forms of glycogen synthase in intact adipose tissue. J. Biol. Chem., 254: 4674 (1979).

23. Kikkawa, Y., Kiabara, M., Motoyama, E. K., Orzalesi, M. M., and Cook, C. D.: Morphologic development of fetal rabbit lung and its acceleration with cortisol. Am. J. Pathol., 64: 423 (1971).

24. Krebs, E. G. and Preiss, J.: In: Biochemistry, Series I. Kornberg, H. L., and Phillips, D. C., editors. Vol. 5 p. 339 (Baltimore, University Park, 1975).

25. Lowry, O. H., Rosebrough, N. J., Farr, A. L., and Randall, R. J.: Protein measurement with the folin phenol reagent. J. Biol. Chem., 193: 265 (1951).

26. Lowry, O. H. and Passoneau, J. V.: A Flexible System of Enzyme Analysis. Academic Press, N.Y. (1972).

27. Maniscalco, W. M., Wilson, C. M., Gross, 1., Gobran, L., Rooney, S. A., and Warshaw, J. B.: Development of glycogen and phospholipid metabolism in fetal and newborn rat lung. Biochim. Biophys. Acta, 530: 333 (1978).

28. Mason, R. J., Nellenbogen, J., and Clements, J. A.: Isolation of disaturated phosphatidylcholine with osmium tetroxide. J. Lipid Res., 17: 281 (1976).

29. Motoyama, E. K., Orzalesi, M. M., Kikkawa, Y., Kiabara, M., Wu, V., Zigas, C. J., and Cook, C. D.: Effect of cortisol on the maturation of fetal rabbit lung. Pediatrics, 48 : 547 (1971).

30. Pitkin, R. M. and Van Orden, D. E.: Fetal effects of maternal streptozotocin diabetes. Endocrinology, 94: 1247 (1974).

31. Robert, M. F., Neff, R. K., Hubbell, J. P., Taeusch, H. W., and Avery, M. E.: The association between maternal diabetes and the respiratory distress syndrome in the newborn. N. Engl. J. Med., 294: 357 (1976).

32. Rooney, S. A., Gobran, L. I., Marino, P. A., Maniscalco, W. M., and Gross, I.: Effects of betamethasone on phospholipid content, composition and biosynthesis in the fetal rabbit lung. Biochim. Biophys. Acta, 572: 64 (1979).

33. Rooney, S. A.: Personal communication (1980).

34. Rosselin, G., Assan, R., Yalow, R. S., and Burson, S. A.: Separation of antibody bound and unbound peptide hormone labelled with 1-131 by talcum powder and precipitated silica. Nature, 212: 355 (1966)

35. Rhoades, R. A., Eller, D. A., and Vannata, B.: Influence of maternal diabetes mellitus on lipid metabolism in neonatal rat lung. Biochim. Biophys. Acta, 572: $132(1979)$.

36. Salisbury-Murphy, S., Rubinstein, S., and Beck, J. C.: Lipid metabolism in lung slices. Am. J. Physiol., 211: 988 (1966).

37. Saugmann, P.: Glycogen synthase "R": The occurrence and significance of a previously unknown form of GS, found in metabolically active human leucocytes. Biochem. Biophys. Res. Commun., 74: 1511 (1977).

38. Schwartz, A. L., Raiha, N. C. R., and Rall, T. W.: Hormonal regulation of glycogen metabolism in the human fetal liver: 1. Normal development and effects of dibutyryl cyclic AMP, glycogen, and insulin in liver explants. Diabetes, 24: 1101 (1975)

39. Sosenko, I. R. S., Frantz, I. D., Roberts, R. J., and Meyrick, B.: Morphologic disturbance of lung maturation in fetuses of alloxan diabetic rabbits. Am. Rev. Resp. Dis., I22: 687 (1980).

40. Sosenko, I. R. S., Lawson, E. E., Demottaz, V., and Frantz, I. D.: Functional delay in lung maturation in fetuses of diabetic rabbits. J. Appl. Physiol., 48: $643(1980)$.

41. Stalmans, W. and Hers, H. G.: The stimulation of liver phosphorylase B by AMP, fluoride, and sulfate. Eur. J. Biochem., 54: 341 (1975).

42. Tierney, D. F. and Levy, S. E.: The Biochemical Basis of Pulmonary Function: vol. 2. Crystal R. G., Editor. p. 105 (Decker, New York, New York 1976).

43. Tyden, O., Berne, C., and Eriksson, V.: Lung maturation in fetuses of diabetic rats. Pediatr. Res., 14: 1192 (1980).

44. Williams, M. C. and Mason, R. J.: Development of the type Il cell in the fetal rat lung. Am. Rev. of Resp. Dis., 115: 37 (1977).

45. This research was supported in part by NIH grant \#HD 07094 and HD 08293

46. We thank Dr. Rosa Hendler for performing the insulin assays and Debra Camputaro for assistance with the manuscript.

47. Dr Gewolb's present address: Department of Pediatrics, Albert Einstein College of Medicine, Bronx, NY 10461.

48. Requests for reprints should be addressed to: Dr. Joseph B. Warshaw, Department of Pediatrics, University of Texas Southwestern Medical School, 5323 Harry Hines Blvd., Dallas, TX 75235.

49. Received for publication January $8,1982$.

50. Accepted for publication April 22, 1982. 